\title{
Multiple Thoracic Hydatidosis: A Case Report
}

\author{
Mona Mlika ${ }^{*}$, Aida Ayadi-Kaddour and Faouzi El Mezni \\ ${ }^{I}$ Department of Pathology. Abderrahman Mami Hospital, Search Unit: 02- SU- 08/08, Ariana, Tunis, Tunisia
}

\begin{abstract}
Background: Multiple thoracic hydatidosis is uncommon even in endemic countries.
Case Presentation: A 37-year-old Caucasian man came to our observation with a 10-day history of basi-thoracic chest pain and dyspnea. Chest X-ray showed a well limited cardiac opacity associated to an opacity of the upper lobe of the right lung. Chest CT-scan showed a mediastinal cyst evoking a hydatid cyst in the left ventricle associated to a right pleural effusion. The patient underwent surgery that consisted in the drainage of multiple pericardial cysts, cystectomy of a left ventricle cyst and right pleural cystectomy. Microscopic examination showed a pleuro-pulmonary and cardiopericardial hydatidosis. The patient was treated with albendazole and did not present complications or recurrences after one year of follow up.

Conclusion: Multiple thoracic hydatidosis is rare. Cardiac location is most challenging because it is difficult to manage and life threatening. Treatment modalities continue to be based mainly on surgery. Preventive measures are necessary to avoid disease recurrence.
\end{abstract}

Keywords: Thorax, hydatidosis, treatment.

\section{INTRODUCTION}

Hydatid disease is an endemic zoonosis caused by the tapeworm Echinococcus Granulosus. Infestation is confined to geographic areas where there is continuous contact between humans and dogs, cats or sheep. Echinococcus Granulosus tapeworms develop mainly in the liver and lungs. Cardiac involvement is an uncommon presentation mainly occurring as part of a systemic infection [1].

\section{CASE PRESENTATION}

A rural 37-year-old Caucasian man presented to us with a 10-day history of basi-thoracic chest pain and dyspnea. Chest X-ray showed a well limited cardiac opacity associated to an opacity of the upper lobe of the right lung. Chest CT-scan showed a mediastinal cyst evoking a hydatid cyst in the left ventricle associated to a right pleural effusion (Fig. 1a).

Hydatid serology was positive. Per-operatory exploration showed a cardio-pericardial and left pleural hydatidosis. Drainage of multiple pericardial cysts, cystectomy of a left ventricle cyst and right pleural cystectomy were performed. Microscopic examination showed a pleuro-pulmonary and cardio-pericardial hydatidosis characterized by the presence of inflammation with granulation tissue and a foreign-body reaction surrounding an eosinophilic laminar material (Fig. 1b, c). The patient was treated with Albendazole and did not present complications or recurrences after one year of follow up.

\section{DISCUSSION}

Hydatidosis is a public health issue in many countries. In humans, it is a zoonotic infection caused by larval stages

Address correspondence to this author at the Department of Pathology. Abderrahman Mami Hospital, Ariana. 2037, Tunis, Tunisia; Tel: 00216 98538 862; E-mail: mlika.zorgati.mona@hotmail.com (metacestodes) of cestode species of the genus Echinococcus. The definitive hosts for the adult cestode are carnivores, commonly the domestic dog for E. granulosus and the fox for E. multilocularis. The adult tapeworms which may number several thousands in the heavily infected dog intestine, shed both eggs and gravid proglotids, which can be found in the host's stool. Human and natural intermediate hosts become infected when they swallow these immediately infective eggs. In the duodenum, the larvae or onchospheres are freed and using their hooklets, find their way through the intestinal mucosa into the lumen of blood vessels [2]. They are then carried by the blood until they lodge in capillaries at almost any site. Liver is the most frequently affected organ (50- 70\%), followed by the lungs $(25-40 \%)$. Cardiac hydatidosis is rare, representing 0.5 to $2 \%$ of all locations. Left ventricle $(60 \%)$ and inter-ventricular septum (9-20\%) are more frequently involved. Signs and symptoms depend on the location of the cysts. Cysts located in the cardiac cavities, especially in the left ventricle, mimic symptoms of valvulopathies. Intra-cavitary cysts induce a pressure resulting in congestive cardiac deficiency. The cysts located in the inter-ventricular septum may cause atrio-ventricular block. Physical examination may show signs evoking mitral stenosis due to left auricular cysts. Hepatic enlargement with hepato-jugular reflux may be observed in patients with hydatid cysts of the right ventricle.

The diagnosis is based on ultra-sound examination, CTscan and serology. Microscopic examination confirms the diagnosis by showing laminar eosinophilic material. The main differential diagnosis is with fibrillary deposits which don't induce inflammation, granulation tissue and foreign body reaction. Besides, laminar hydatid material reacts with the Periodic Acid Schiff coloration [3].

The main complications are infection, biliary duct fistula and rupture into the peritoneum or chest, which can cause anaphylactic shock and pneumothorax. Treatment is based 


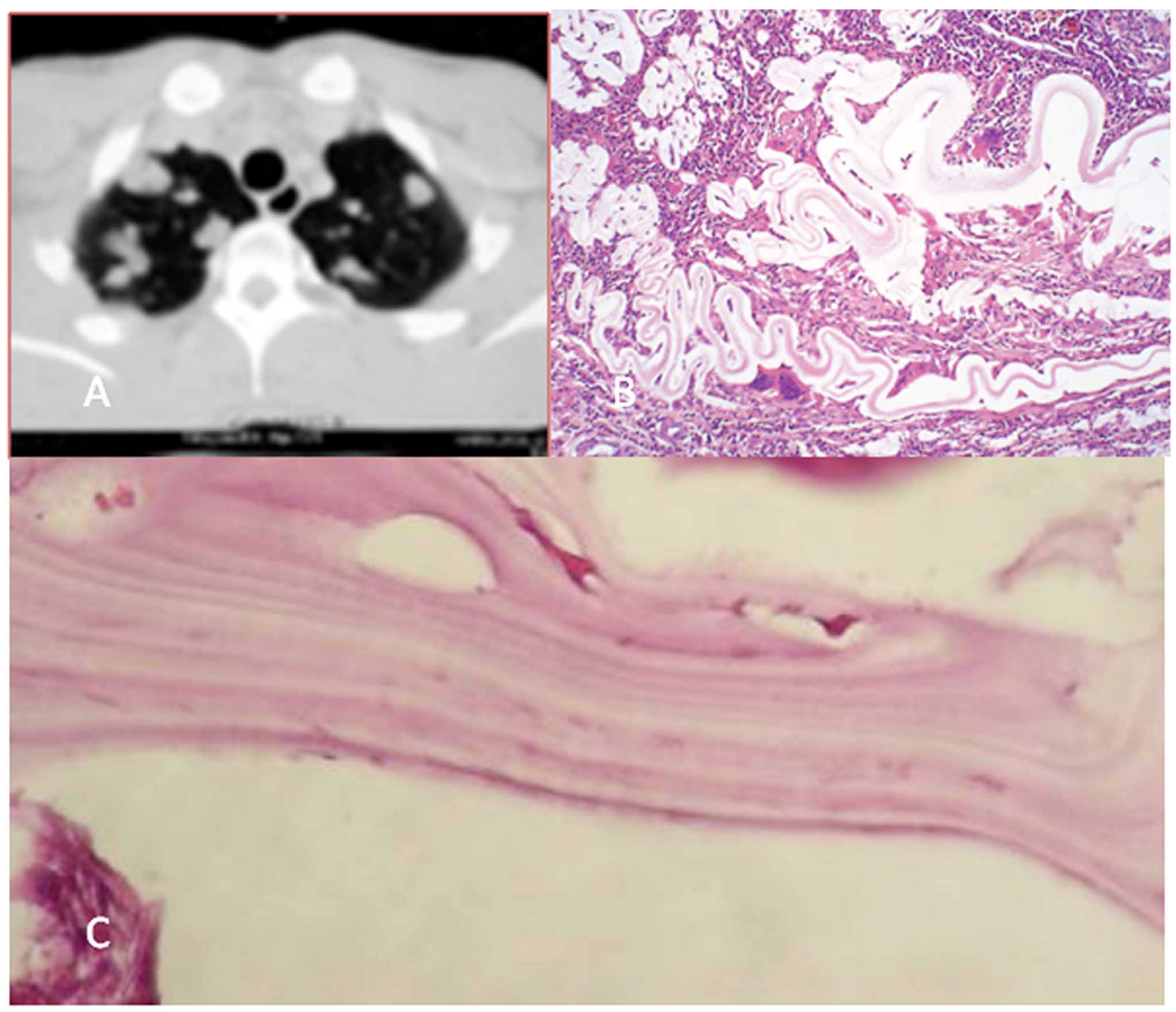

Fig. (1). (a) Chest CT-scan: mediastinal cyst evoking a hydatid cyst in the left ventricle associated to a right pleural effusion, (b) Granulation tissue and foreign-body reaction surrounding an eosinophilic laminar material (HE x 250), (c) Hydatid membranes at high magnification (HE $\mathrm{x}$ 400).

mainly on surgical management with extra corporeal circulation. However surgical management is challenging because of the possible risk of rupture, infectious contamination and pulmonary embolism which induce some surgeons to systematically clamp the main pulmonary artery in order to prevent the migration of cysts or vesicles through the general circulation that can cause anaphylactic shock. Cystectomy and pericystectomy remain the most useful surgical techniques [4].

Patient consent section: Written informed consent was obtained from the patient for publication of this case report and accompanying images. A copy of the written consent is available for review by the Editor-in-Chief of this journal.
Authors contribution section: $\mathrm{MM}$ observed the case and wrote the manuscript. AA and FM performed the histological examination and contributed to manuscript writing. All authors read and approved the final version.

\section{ACKNOWLEDGEMENT}

Declared none.

\section{CONFLICT OF INTEREST}

Declared none.

\section{REFERENCES}

[1] Canpolat U, Yorgun H, Sunman H, Aytemir K. Cardiac hydatid cyst mimicking left ventricular aneurysm and diagnosed by magnetic resonance imaging. Turk Kardiyol Dern Ars 2011; 39(1): 47-51. 
[2] Gentile F, Litvak E, Gay C, Mateos F, Salgueiro F, Moscatelli G. Liver hydatidosis. Arch Argent Pediatr 2010; 108: 559-60.

[3] Kelle S, Kohler U, Thouet T, Fleck E, Nagel E. Cardiac involvement of Echinococcus Granulosus evaluated by multicontrast CMR imaging. Int J Cardiol 2009; 131: 59-60.
[4] Orhan G, Ozay B, Tartan Z, et al. Chirurgie des kystes hydatiques cardiaques. Trente-neuf ans d'expérience. Ann Cardiol Angeiol (Paris) 2008; 57: 58-61.

Received: December 14, 2011

(C) Mlika et al.; Licensee Bentham Open.

This is an open access article licensed under the terms of the Creative Commons Attribution Non-Commercial License (http://creativecommons.org/licenses/ by-nc/3.0/) which permits unrestricted, non-commercial use, distribution and reproduction in any medium, provided the work is properly cited. 